\title{
A comparative study on CdSe synthesized at low temperature
}

\author{
H PADMANABHA SARMA*, V SUBRAMANIAN, N RANGARAJAN \\ and K R MURALI \\ Central Electrochemical Research Institute, Karaikudi 623006, India
}

MS received 21 May 1994; revised 9 August 1995

\begin{abstract}
CdSe is a well-known semiconductor which finds applications as photoconductors, photovoltaic cells and other optoelectronic devices. In this paper structural studies and carrier concentration measurements of vacuum evaporated CdSe films obtained by using CdSe synthesized by simple precipitation technique are presented.
\end{abstract}

Keywords. II-VI semiconductor; CdSe; thin film.

\section{Introduction}

The II-VI semiconducting compounds viz. sulphides, selenides and tellurides of cadmium find applications as photoconductors (Buragohain and Barua 1987) and electro optical devices (Yukami et al 1986). Amongst the chalcogenides, CdSe exhibits maximum photoconductivity. In view of this, CdSe is being actively investigated. Earlier workers synthesized CdSe by several methods (Trekhora 1975; Ostrovskaya et al 1976). However, only a few have adopted the direct synthesis method (mixing of both the elements). For laboratory investigations, the most convenient way of obtaining high purity compounds, is by synthesis from elements. In the case of vapour phase reactions, this is usually rather difficult and from many points of view, impractical. On the other hand, synthesis by reaction of the molten elements may be either too slow for practical purposes (Reisman and Birkenblitt 1963) or too rapid (Korneeva et al 1960), thus causing detonations. To avoid these difficulties, a novel method was adopted for the first time to synthesize CdSe. The results obtained on evaporated films prepared using the synthesized CdSe are reported in this paper.

\section{Experimental}

In the present method, CdSe has been obtained by the reaction of a mixture containing cadmium and selenium solvents in the presence of a reducing solution. This technique consists of preparing a reducing solution and also the corresponding elemental solvents. All the chemicals used here are of analytical reagent grade. The reducing solution was prepared from $4 \mathrm{~g}$ of tartaric acid, $60 \mathrm{ml}$ of hydrazine hydrate, $30 \mathrm{ml}$ of distilled water and $50 \mathrm{ml}$ of ammonia. $1.12 \mathrm{~g}$ of cadmium in $24 \mathrm{ml}$ of 1:4 nitric acid and $0.79 \mathrm{~g}$ of selenium in $28 \mathrm{ml}$ of aqua regia were the source for the elemental solvents. The cadmium solution was added first to the reducing solution at $363 \mathrm{~K}$ and then the selenium solution was added. A precipitate was formed at the bottom of the flask. This was filtered and washed with distilled water and the process was continued till the $\mathrm{pH}$ of the filtrate was found to be neutral. Then again it was washed with hot $\mathrm{KOH}$ to remove unreacted selenium. Finally, it was kept at $573 \mathrm{~K}$ in argon atmosphere for $5 \mathrm{~min}$. CdSe films were thermally evaporated on cleaned glass and Ti substrates kept at room 
temperature. The deposition conditions are summarized below:

\begin{tabular}{ll}
\hline Vacuum & $10^{-5} \mathrm{Torr}$ \\
Source temperature & $1073 \mathrm{~K}$ \\
Source of substrate separation & $12 \mathrm{~cm}$ \\
Deposition time & $5 \mathrm{~min}$ \\
Source material & CdSe \\
Substrates & Glass and titanium \\
\hline
\end{tabular}

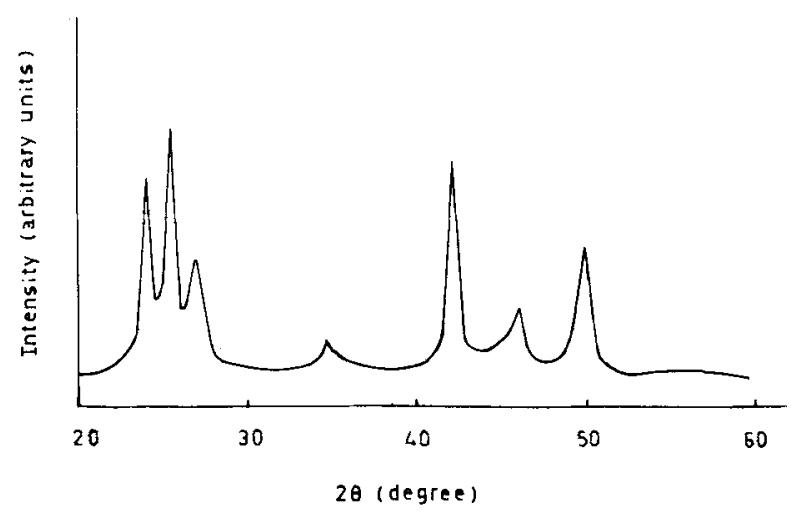

Figure 1. X-ray diffractogram of synthesized CdSe.

For comparison, films were also made by using the commercially available $\mathrm{CdSe}(\mathrm{M} / \mathrm{s}$ Koch-Light, UK).

\subsection{Characterization}

The possible impurities observed in the synthesized CdSe were estimated using atomic absorption spectrophotometer (AAS) (Perkin-Elmer model 380). Using Jeol JDX

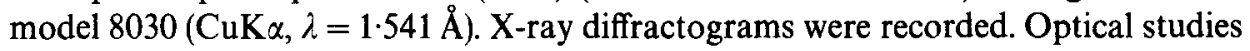
were carried out in the wavelength range of $550-800 \mathrm{~nm}$ by using Hitachi U-3400 spectrophotometer. The absorbance of the CdSe films for each wavelength can be obtained by using this spectrophotometer. The substrate absorption, if any, was corrected by introducing an uncoated glass substrate of the same size in the reference beam.

The absorption coefficient $\alpha$ is calculated by using the relation

$$
\alpha=\frac{2 \cdot 303 A}{t}
$$

where $A$ is the absorbance value at a particular wavelength and $t$ the thickness of the film. The film thickness is estimated by adopting a nondestructive technique. namely the gravimetric method (Yeh and Blakeslee 1963). Here $t$ for the films are $0.31 \mu \mathrm{m}$ (synthesized CdSe) and $0.309 \mu \mathrm{m}$ (commercial one). 
Table 1. Elemental analysis (in ppm).

\begin{tabular}{lcccccccccc}
\hline Material & $\mathrm{Tl}$ & $\mathrm{K}$ & $\mathrm{Na}$ & $\mathrm{Fe}$ & $\mathrm{Pb}$ & $\mathrm{Cu}$ & $\mathrm{Zn}$ & As & $\mathrm{Co}$ & $\mathrm{Ca}$ \\
\hline $\begin{array}{l}\text { CdSe } \\
\text { (Prepared) }\end{array}$ & 20 & 10 & 9 & - & - & - & 5 & - & - & 115 \\
$\begin{array}{l}\text { CdSe } \\
\text { Imported) }\end{array}$ & 16 & 7 & 5 & - & - & - & 3 & - & - & 110 \\
\hline
\end{tabular}

The absorption coefficient $\alpha$ for a band transition between parabolic bands is given by

$$
\alpha=\frac{\beta}{h v}(h v-E g)^{n / 2},
$$

where $\beta$ is the constant depending upon the transition probability, $h v$ the radiation energy and $n=1$ or 4 depending upon direct or indirect transition, respectively. A

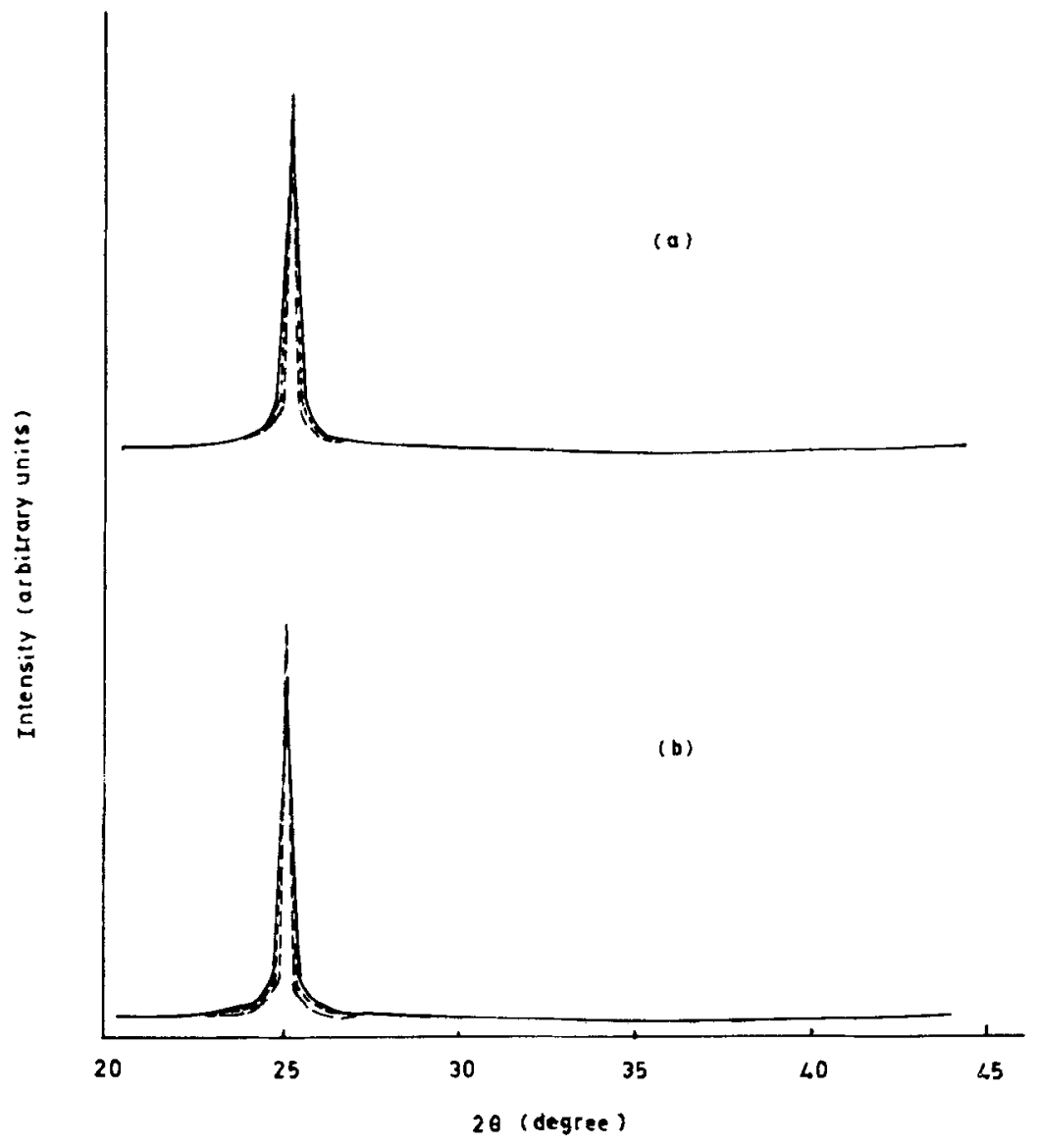

Figure 2. X-ray diffractogram of CdSe films obtained from (a) the synthesized and (b) commer-

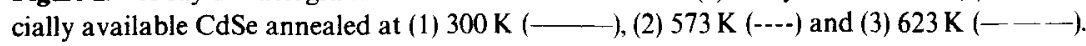


plot of $(\alpha h v)^{2}$ or $(\alpha h v)^{1 / 2}$ against $(h v)$ exhibits a straight line, whose intercept on the $h v$ axis is the energy band gap for direct or indirect transition respectively and the slope is $\beta$. Impedance measurements were made by using PAR electrochemical analyser for the film deposited on Ti substrates. Measurements on films were carried out after annealing at $473 \mathrm{~K}$ in air and argon atmospheres for $5 \mathrm{~min}$ in separate experiments. Here a three electrode system with $\mathrm{Pt}$ as the counter electrode, $\mathrm{CdSe}$ on $\mathrm{Ti}$ as the working electrode and SCE as the reference electrode was used. $1 \mathrm{M}\left(\mathrm{Na}_{2} \mathrm{SO}_{4}\right)$

Table 2. Crystallite size of the films.

\begin{tabular}{lccc}
\hline & \multicolumn{3}{c}{ Crystallite size $(\AA)$} \\
\cline { 2 - 4 } & \multicolumn{3}{c}{ Film annealed at } \\
\cline { 2 - 4 } Film deposited from & $300 \mathrm{~K}$ & $573 \mathrm{~K}$ & $823 \mathrm{~K}$ \\
\hline CdSe (Prepared) & 210 & 215 & 326 \\
CdSe (Imported) & 300 & 322 & 626 \\
\hline
\end{tabular}

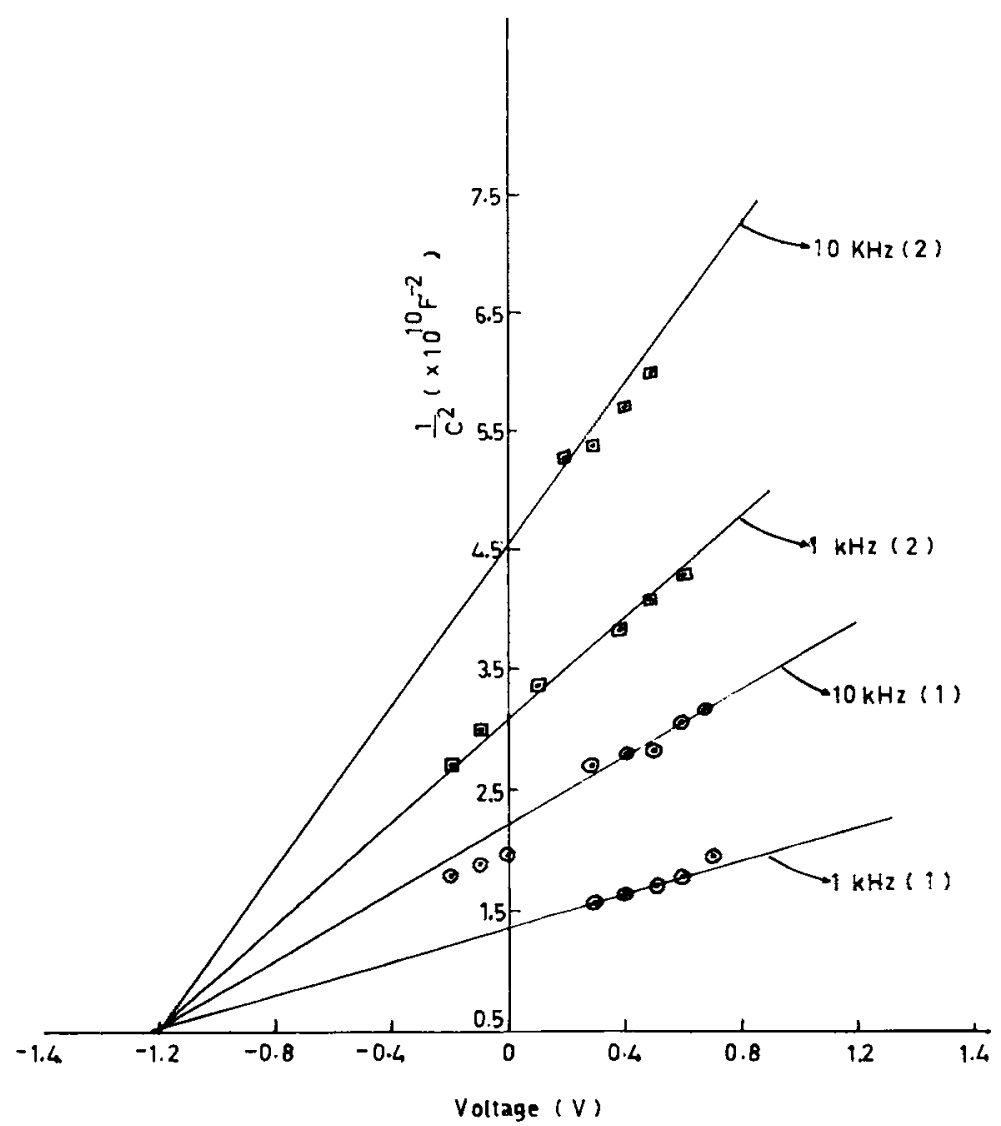

Figure 3. Mott-Schottky plot for CdSe films annealed at $473 \mathrm{~K}$ in (1) air and (2) argon atmospheres. 
was used as the electrolyte. DC potenual in the range of +700 to $-200 \mathrm{mV}$ corresponding to the two frequency ranges 1 and $10 \mathrm{kHz}$ was applied to the films (area of the film is $0 \cdot 15 \mathrm{~cm}^{2}$ ). Capacitance of the films was computed from the observed values of $z^{\prime \prime}$ (imaginary part of the impedance which is equal to $1 /(2 \times 3.14 \times$ frequency $\times$ capacitance)).

\section{Results and discussion}

X-ray diffractogram of the prepared CdSe (figure 1) exhibited almost all the refiections corresponding to single phase hexagonal CdSe. The prominent peaks were observed at $2 \theta=23.9^{\circ}, 25 \cdot 4^{\circ}, 27.08^{\circ}, 35 \cdot 1^{\circ}, 41.8^{\circ}, 45 \cdot 78^{\circ}$ and $49 \cdot 6^{\circ}$ having reflections (100), (002), (101), (102), (110), (103) and (112) having reflectivity. The reflections observed in figure 1 are in agreement with ASTM data (ASTM standards). From the diffuse

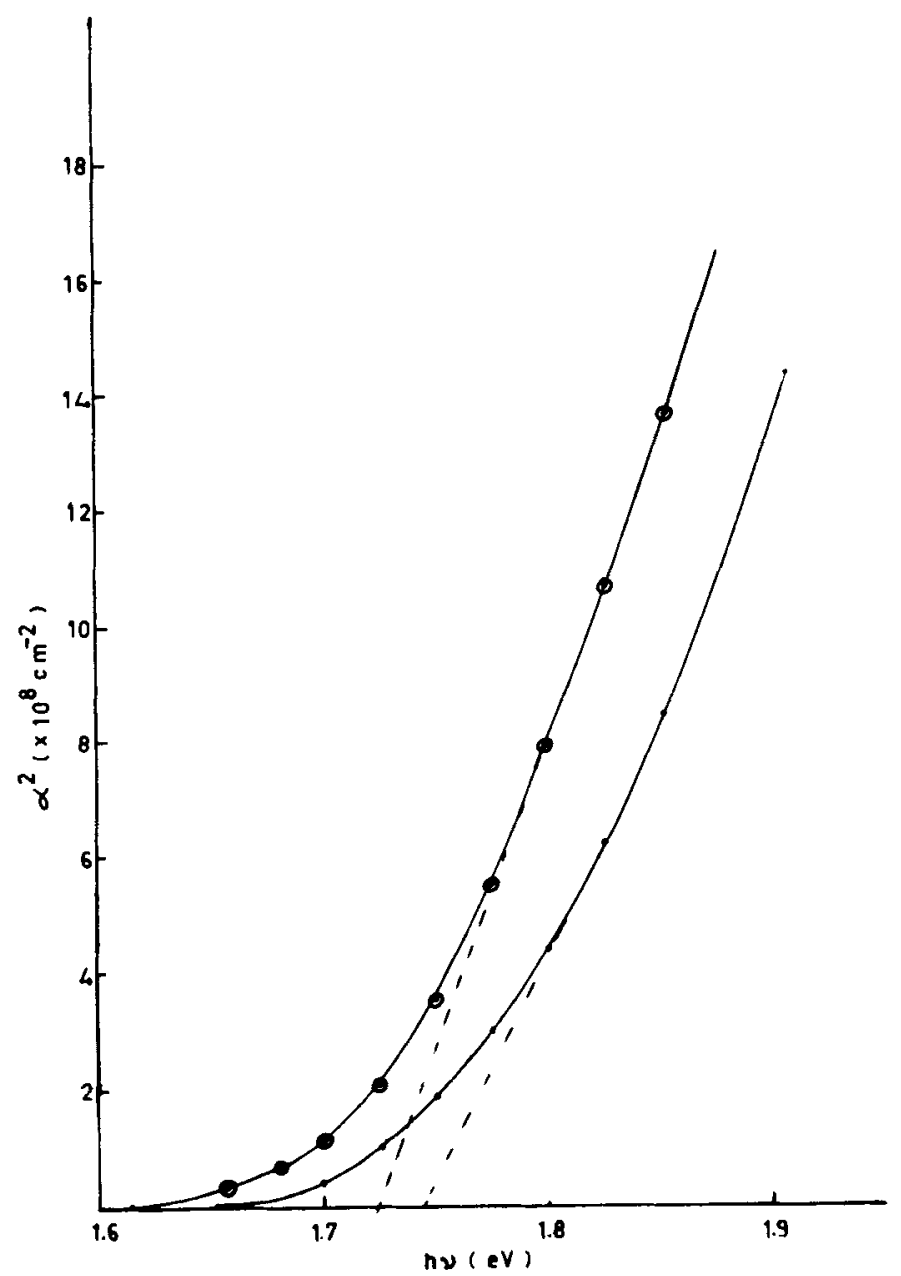

Figure 4. Variation of $\alpha^{2}$ with photon energy (hv) CdSe films obtained by using (1) the synthesized $(\odot)$ and (2) commercially available $\mathrm{CdSe}(\odot)$. 
reflectance spectra it was observed that the energy band gap value is $1.74 \mathrm{eV}$. The purity of the synthesized CdSe was examined by AAS and compared with that of the commercial one, as given in table 1 . The results shown in table 1 clearly suggest that CdSe prepared in the laboratory is of comparable purity to the commercially available one.

The X-ray diffractogram as grown films and those annealed at 573 and $823 \mathrm{~K}$ in air exhibit a peak at $2 \theta=25 \cdot 1^{\circ}$ with a preferred orientation in the $(002)$ direction, as shown in figure 2 , indicating the preferential growth of crystallites in this direction. It is also seen from figure 2 that while the peak width decreases with annealing temperature, the peak height increases. These results were obtained on the cleaned glass substrate without any application of electrical/magnetic field during deposition. Similar observations were obtained in the case of both close-spaced vapour transport and conventional evaporated CdS films on glass and mica substrates. Using Scherrer's equation (Cullity 1956), the crystallite size for these films was estimated as given in table 2 . The variation in crystallite size may be due to the difference in the growth rates of the films. The capacitance of the films was of the order of $10^{-6} \mathrm{~F}$. Using Mott-Schottky relation (Chopra and Das 1983), the curves were drawn between $1 / C^{2}$ against $V$, as shown in figure 3 . From figure 3 , it is observed that $1 / C^{2}$ for the air annealed films is less than for the argon annealed films. The carrier concentration was calculated from the slope of figure 3 which was found to be in the range of $10^{21} \mathrm{~cm}^{-3}$. This high value of carrier concentration may be due to the contribution of substrate through micropinholes and microcracks formed in the films during the heat treatment step (Herrasti et al 1990). Also the films were found to be $n$-type in nature as seen from figure 3.

Using the optical transmittance measurements, the absorption coefficient $\alpha$ was determined at various photon energies (Dawar et al 1990). In order to estimate the energy band gap, the results were plotted between $\alpha^{2}$ and $h v$, as shown in figure 4 . The plot is a straight line for both the films indicating the band gap to be direct. The values are 1.74 and $1.72 \mathrm{eV}$, which agree well with the values reported by other workers (Masatoshi et al 1988).

\section{Conclusions}

A novel method has been attempted for the synthesis of CdSe and it is of comparable purity to the commercial one. The present method of preparation possesses the following advantages: economically viable, does not involve the use of hazardous hydrogen selenide, impurity levels are very low, does not involve the costly imported selenourea as normally used in other techniques and involves the use of relatively low temperature i.e. $373 \mathrm{~K}$. The films prepared using both the CdSe exhibit identical XRD and optical characteristics.

\section{References}

ASTM 8-459: $\alpha$-CdSe

Buragohain M and Barua K 1987 Indian J. Phys. A61 559

Cullity B D 1956 Elements of $X$-ray diffraction (Addison-Wesley) p. 99

Chopra K L and Das S R 1983 Thin film solar cells (New York: Plenum) p. 464

Dawar A L, Shishodia P K, Chauhan G, Kumar A and Mathur P C 1990 J. Mater. Sci. Lett. 9547 
Herrasti P, Fats E, Herrero J and Ortega J 1990 Electrochim. Acta 35345

Korneeva J V, Sokolov V V and Novoselova A V 1960 Zh. Neorg. Chim. 5241

Masatoshi F, Tomoj K and Sichio 1988 Sol. Energy Mater. 1823

Ostrovskaya I I, Yatlova L E, Kitaev G A and Dvoinin V I 1976 Zh. Prikl. Khim. 491212

Reisman A and Birkenblitt M 1963 J. Phys. Chem. 6722

Trekhora T S 1975 Khim Tekhnol. 181879

Yeh T H and Blakeslee A E 1963 J. Electrochem. Soc. 1101018

Yukami M, Keda M, Harada Y, Nishitam M and Nishikura T 1986 IEEE Trans. Electron Devices ED 33520 